\title{
Review of six Japanese online citizen science projects with main indicators to encourage citizen motivation
}

\author{
Eiri Ono *\#, Yuko Ikkatai ${ }^{\dagger}$, Teruaki Enoto \\ \# equally contributed
}

\begin{abstract}
Universities and research institutions have recently been preparing for open science. Open science includes various concepts such as open data and open access. Scientific activities participated in with citizens who are not specialists in the field are traditionally called citizen science. The recent developments of web-based information and communication technology (ICT) have further changed the methods and styles of citizen science. This new generation of web-based citizen science is referred to as "crowd science" in this study. Crowd science projects have gradually been launched in Japan as web-based data-collection and data-processing projects. However, what factors mainly contribute to the improvement of these Japanese projects are yet to be reviewed. In this article, six Japanese crowd science projects are reviewed and classified on the basis of levels of online citizen participation. It is suggested that super-volunteers, who are enthusiastic members of the project, should become key players for the growth of the project. Furthermore, it is revealed that online discussion forums have played a major role in enhancing participants' communication. These forums result in fruitful discussions and achievements of the project. Knowledge of these key components is beneficial not only for future project organizers but also for universities and research institutions.
\end{abstract}

Keywords: open science, citizen science, crowd science, super-volunteers, Japan

\section{Introduction: Trends of open science}

Open science is now spreading throughout the world. It is an umbrella term that includes more than 30 concepts such as open access and open data [1-3]. Open access and open data are becoming essential aspects of the information infrastructure of research activities. Recently, universities and research institutions have been preparing for open science; for example, Kyoto University in Japan adopted the Kyoto University Open Access Policy in 2015 [4]. In addition, collaborative work, which is based on these major concepts, has been considered [1]. Among various types of collaborations, citizen-participatory science has recently had a significant academic impact. Universities and research institutions will be required to deal with this type of science in the near future in terms of public relations, evaluation of collaborative researches, and science communication.

\footnotetext{
* Kyoto University, Kyoto, Japan

†higa University, Shiga, Japan

* Kyoto University, Kyoto, Japan
} 
Scientific activities that are conducted by citizens who are not regarded as specialists in the particular field are traditionally referred to as citizen science [5]. An example of citizen science is the Christmas Bird Count, which is an annual, nationwide, volunteer-based bird survey that began in the 1990s and is organized by the Audubon Society in the United States. The aim of this survey is to assess long-term trends of bird populations in winter [6]. Online information and communication technology (ICT) has been changing the collaboration styles and methods of citizen science. ICT has enabled many citizens to access and analyze large amounts of data from all over the world [7]. An example of online citizen science is Galaxy Zoo, an aspect of Zooniverse that is organized by the Citizen Science Alliance. Galaxy Zoo is a web-based project for citizen volunteers in which they are required to categorize large numbers of galaxy images by utilizing crowdsourcing techniques [8]. The original motivation was "to study them, assisting astronomers in attempting to understand how the galaxies we see around us formed, and what their stories can tell us about the past, present and future of our Universe as a whole" [9]. This style of online citizen science is also called "networked science", "cyberscience", and" massively collaborative science" $[10,11,12]$. In this paper, we employed the term "crowd science" to emphasize the role of crowds in science.

Online data collection and data processing are ways for volunteers to participate in crowd science projects. eBird, a data collection project organized by the Cornell Lab of Ornithology, provides "rich data sources for basic information on bird abundance and distribution at a variety of spatial and temporal scales" [13]. The official project website affords participants the opportunity to learn the background and purpose of the project as well as has research data and various snippets of news. Furthermore, the website accommodates 10 languages. Citizen volunteers provide eyewitness reports of birds by utilizing an official mobile application or website form. More than 140 million observations had been received from 150,000 users by 2013 [14]. The Galaxy Zoo project is classified as a data-processing project. The official project site accommodates 13 languages and includes the background and purpose of the project as well as data and publications. It is noteworthy that users can communicate with other users through online discussion forums and can freely ask questions when they participate in the classification tasks; 165,000 participants have classified 890,000 images [15]. In addition, in excess of 50 papers have been published on the project [16]. It is difficult to define the success of a project because the purpose of each project and task varies depending upon the project. Whereas continuous data-collection projects like eBird have no apparent periods, data-processing projects like Galaxy Zoo have a limited volume of tasks. Therefore, this study considered citizen motivation rather than the success of projects.

What factors can enhance citizen motivation and contribute primarily to the achievements of crowd science remains a topic for discussion. In the Galaxy Zoo, scientists with sufficient experience provide leadership, which contributes to the scientific success achieved by the volunteers of the project [12]. In general, the participation of faculty members and researchers from universities may increase citizens' confidence in research [17]. Haklay classified citizen science projects into four levels based on citizens' participation and engagement [18]. Level 1 involves crowdsourcing; the participants collect data as "sensors" without any training. Level 2, distributed intelligence, is when the participants collect, process, and/or interpret data after some training. Galaxy Zoo and classic citizen science projects are classified as Level 2. Level 3 is known as participatory science as the problem of the project is defined by citizens with the assistance of experts. Participatory science is usually found in local and environmental studies. The participants are sometimes less involved in the details of scientific analyses. Level 4 is 
referred to as extreme citizen science as both experts and non-professionals are involved and participate in the project by means of collaboration, for instance, in astronomy. Selecting the appropriate level of citizens' participation is believed to enhance participants' activities; this eventually results in achieving the goals of the project. It is noteworthy that continuity among the four levels does not exist, which means a Level 1 project need not advance to Level 4 . Determination of an appropriate level should depend upon the purpose of the project and the involvement of citizens in the research.

Online tools employed for the project do not only provide project information but also enhance the motivation of participants. Free official websites and social networking services are basic ways to provide information to a wide range of people. Online discussion forums, such as Internet discussion boards, allow participants to freely discuss tasks [15, 19], thus contributing to the increased learning motivation of the participants. As volunteers recognize their appropriate roles in the project through the discussion, they tend to commit more to the project [20]. In Zooniverse, the most advanced participants, known as super-users, enthusiastically commit to the project for a long period. Approximately $4 \%-7 \%$ of super-users are involved in $85 \%$ of all the tasks [21]. User motivation varies, spanning contributing to a scientific process, interest in the project, and fun [22]. Adopting gamification, which is a process that integrates game mechanics in non-game contexts, that is, user ranking in a project, enhances citizens' interest in the project [23]. Funding is important not only for planning crowd science projects but also for examining citizens' participation in the project. Online donations and crowdfunding by citizens are direct ways to express motivation in the projects.

Crowd science projects have gradually started in Japan. Although the factors that contribute to the successful completion of crowd science projects have been examined in worldwide projects [12], these have not yet been explored in Japanese projects. In this study, we aim to classify and review on Japanese crowd science projects, which may be useful for future project organizers in Japan. We have been organizing the Kyoto Open Science (KOS) study group to examine the key factors to enhance citizen science. In the previous proceeding [24], we proposed three factors as key elements at both offline and face-to-face workshops so as to motivate citizens to participate in crowd science, namely, the topic, common space, and method. First, the project topic should be attractive to the various stakeholders, including both specialists and non-specialists; this is referred to as "boundary objects" [25]. Second, the location of the offline workshop should be a common space where anyone can gain easy access rather than closed locations such as universities. Third, using an appropriate selection of methods is important. For example, we conducted Ideathon, which is a coined word comprising an idea and a marathon that encourages communication among participants, in our previous workshop [24]. Contrary to our previous work on offline workshops, in this study, we investigated online activities that encourage Japanese citizens to participate in crowd science projects.

\section{Case studies of Japanese crowd science projects}

\subsection{Kyoto Open Science study group}

We have been organizing the KOS study group since June 2016 to enhance discussions on the recent developments in crowd science and the relationship between researchers and citizens. We have arranged monthly meetings, which are referred to as KOS meetups. Furthermore, we invited one speaker of a specific project and have had annual roundups, which are called KOS 
workshops [Fig. 1]. Fourteen monthly KOS meetups and two KOS workshops had already been conducted by November 2017. In the meetups and workshops, invited researchers and organizers of crowd science projects discussed project details such as the purposes and organization of the projects. Of the 31 non-researchers at our second workshop, 23 (74\%) indicated in our questionnaire that they would like to participate in citizen science projects [24].

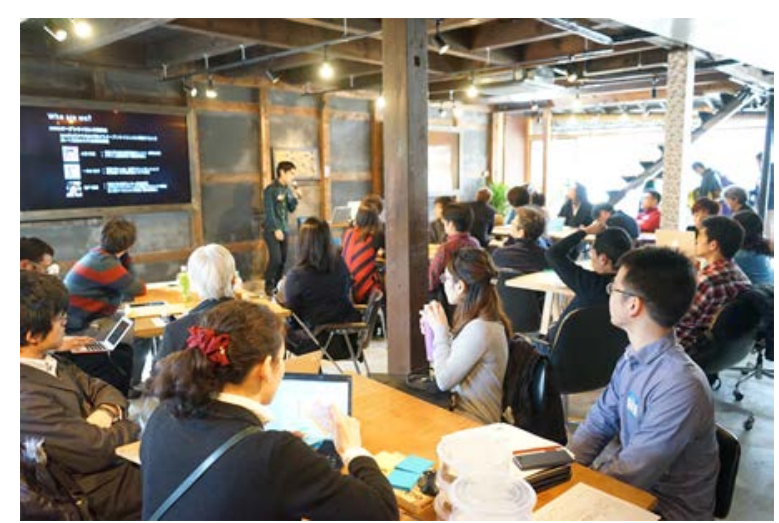

Figure 1: KOS workshop on February 19, 2017.

\subsection{Methods of review}

We reviewed six Japanese projects-Weathernews, Aurora 4D Project, Finding Slugs Project, Minna De Honkoku ("Transcribe With Everyone"), Thundercloud Project, and Safecast - and two worldwide projects as references-Galaxy Zoo and eBird. For the previous 17 months, we have requested the principal members of Weathernews, Aurora 4D Project, Finding Slugs Project, Minna De Honkoku, and Thundercloud Project to present a talk at our KOS meetups or annual workshops. A researcher who investigated Safecast gave a lecture, and we participated in one of the Safecast workshops in Kyoto [26]. In addition, we participated in online tasks for Weathernews, Minna De Honkoku, and Thundercloud Project so as to understand their projects. Through the KOS activities, we obtained the project information: topics and online systems. We classified these projects from Levels 1 to 4 according to Haklay's classification; this was outlined in the Introduction [18].

We investigated each project based on online activity with regard to citizen participation. We examined the six factors thus outlined as indicators of online activities: (1) online discussion forums enhance interactive user communication and allow experts and volunteers to talk freely about their questions; (2) super-volunteers, namely, super-users in the case of Galaxy Zoo, contribute to the developments and achievements of a project. A user ranking on project websites is sometimes utilized to enable visible user contribution. We regarded participants as super-volunteers if they are in the top level of rankings on the project website and repeatedly post or process data in large quantities; (3) online donations and crowdfunding are good indicators of the engagement and support received from citizens. We did not consider financial support from private companies and national funds as online activities because such support does not reflect citizen participation; (4) official mobile applications encourage casual participation. Mobile devices with cameras and sensors, such as GPS and an acceleration sensor, can be employed as effective tools for crowd science; (5) Twitter or Facebook is important for public relations. Although exhibiting project information on an official website has the potential to reach citizens, they are not usually aware of the existence of the website without other online 
media such as Twitter and/or Facebook; and (6) the number of Twitter followers may be an indication of the popularity of a project.

We also investigated key facts of the projects, namely, the year of launch, project type (data collection or data processing), total data collected or processed, and the number of principal members who organize and administer the project. It should be noted that the amount of data cannot simply be compared among projects; whereas data-collecting projects have no limits on the amount of collected data, data-processing projects have a predefined amount of data that need to be processed.

\subsection{Description of crowd science projects in Japan}

In this section, individual crowd science projects launched in Japan are described. Based on the discussions at KOS meetups and workshops as well as document surveys of published papers and websites, we classified eight crowd science projects into four levels and investigated their online activities. The classification and key facts are summarized in Table 1 and Table 2.

Table 1: Classification and indicators of citizen participation

\begin{tabular}{|c|c|c|c|c|c|c|c|}
\hline $\begin{array}{l}\text { Project } \\
\text { Name }\end{array}$ & $\begin{array}{l}\text { Haklay's } \\
\text { Classification }\end{array}$ & $\begin{array}{l}\text { Discussion } \\
\text { Forum }\end{array}$ & $\begin{array}{l}\text { Super- } \\
\text { volunteer }\end{array}$ & $\begin{array}{l}\text { Donation/ } \\
\text { Crowdfunding }\end{array}$ & $\begin{array}{l}\text { Official } \\
\text { Application }\end{array}$ & $\begin{array}{l}\text { Twitter or } \\
\text { Facebook }\end{array}$ & $\begin{array}{l}\text { Followers } \\
\text { on Twitter } \\
*_{5}\end{array}$ \\
\hline $\begin{array}{l}\text { Weather } \\
\text { news }\end{array}$ & 1 - Crowdsourcing & $\sqrt{ }^{* 1}$ & $\mathrm{NA}^{* 2}$ & - & $\checkmark$ & $\mathrm{T} / \mathrm{F}$ & 80,347 \\
\hline $\begin{array}{l}\text { Aurora } \\
4 D \\
\text { Project }\end{array}$ & $\begin{array}{l}1 \text { - Crowdsourcing } \\
\text { and } 2 \text { - Distributed } \\
\text { intelligence }\end{array}$ & - & - & - & - & $\mathrm{T}$ & 100 \\
\hline $\begin{array}{l}\text { Finding } \\
\text { Slugs } \\
\text { Project }\end{array}$ & $\begin{array}{l}1 \text { - Crowdsourcing } \\
\text { and } 2 \text { - Distributed } \\
\text { intelligence }\end{array}$ & - & - & - & - & $\mathrm{T}$ & 785 \\
\hline $\begin{array}{l}\text { Minna } \\
\text { De } \\
\text { Honkoku }\end{array}$ & $\begin{array}{l}2 \text { - Distributed } \\
\text { intelligence }\end{array}$ & $\checkmark$ & $\checkmark$ & - & $\checkmark$ & $\mathrm{T} / \mathrm{F}$ & 372 \\
\hline $\begin{array}{l}\text { Thunder } \\
\text { cloud } \\
\text { Project }\end{array}$ & $\begin{array}{l}2 \text { - Distributed } \\
\text { intelligence }\end{array}$ & - & - & Crowdfunding & - & - & - \\
\hline Safecast & $\begin{array}{l}3 \text { - Participatory } \\
\text { science }\end{array}$ & $\checkmark$ & $\mathrm{NA}^{* 2}$ & $\begin{array}{l}\text { Donation and } \\
\text { crowdfunding }\end{array}$ & $\checkmark$ & $\mathrm{T}^{* 3} / \mathrm{F}^{* 4}$ & 3,176 \\
\hline $\begin{array}{l}\text { Galaxy } \\
\text { Zoo }\end{array}$ & $\begin{array}{l}2 \text { - Distributed } \\
\text { intelligence }\end{array}$ & $\checkmark$ & $\checkmark$ & - & $\checkmark$ & $\mathrm{T} / \mathrm{F}$ & 13,610 \\
\hline eBird & $\begin{array}{l}2 \text { - Distributed } \\
\text { intelligence }\end{array}$ & $\sqrt{ }^{* 1}$ & $\checkmark$ & Donation & $\checkmark$ & $\mathrm{T} / \mathrm{F}$ & 17,008 \\
\hline
\end{tabular}

*1: Comment function; *2: NA = Not Available; *3: Twitter; *4: Facebook; *5: As of Nov. 26, 2017 
Table 2: Key facts

\begin{tabular}{|c|c|c|c|c|c|c|c|}
\hline Project name & Country & Topic & $\begin{array}{l}\text { Start } \\
\text { year }\end{array}$ & $\begin{array}{l}\text { Project } \\
\text { type }\end{array}$ & $\begin{array}{l}\text { Total data } \\
\text { collected or } \\
\text { processed }\end{array}$ & $\begin{array}{l}\text { Referen- } \\
\text { ce }\end{array}$ & $\begin{array}{l}\text { Main } \\
\text { members }\end{array}$ \\
\hline Weathernews & $\begin{array}{l}\text { Mainly } \\
\text { Japan }\end{array}$ & Weather & 2005 & Collection & $\begin{array}{l}\text { Over } 29 \text { million } \\
\text { reports }\end{array}$ & 27 & $826^{* 3}$ \\
\hline $\begin{array}{l}\text { Aurora } 4 D \\
\text { Project }\end{array}$ & Japan & Aurora & 2015 & Collection & 26 pictures $^{* 1}$ & 30 & 16 \\
\hline $\begin{array}{l}\text { Finding Slugs } \\
\text { Project }\end{array}$ & Japan & $\begin{array}{l}\text { Slugs, } \\
\text { alien species }\end{array}$ & 2015 & Collection & Over 300 pictures & $*_{2}$ & 1 \\
\hline $\begin{array}{l}\text { Minna De } \\
\text { Honkoku }\end{array}$ & Japan & $\begin{array}{l}\text { Earthquake- } \\
\text { related } \\
\text { historical } \\
\text { documents }\end{array}$ & 2017 & Processing & $\begin{array}{l}\text { Over } 3 \text { million } \\
\text { letters }^{* 1}\end{array}$ & 36 & 17 \\
\hline $\begin{array}{l}\text { Thundercloud } \\
\text { Project }\end{array}$ & Japan & Gamma rays & 2015 & Processing & Over 7,000 data $^{{ }^{* 1}}$ & 39 & 7 \\
\hline Safecast & $\begin{array}{l}\text { Mainly } \\
\text { Japan }\end{array}$ & $\begin{array}{l}\text { Environmental } \\
\text { radiation }\end{array}$ & 2011 & Collection & $\begin{array}{l}\text { Over } 40 \text { million } \\
\text { data points }\end{array}$ & 43 & 38 \\
\hline Galaxy Zoo & Worldwide & Astronomy & 2007 & Processing & 890,000 images & 9 & 49 \\
\hline eBird & Worldwide & Birds & 2002 & Collection & $\begin{array}{l}\text { Over } 140 \text { million } \\
\text { observations }\end{array}$ & 13 & 22 \\
\hline
\end{tabular}

*1: As of Nov. 26, 2017; *2: In personal communication; *3: Number of employees of Weathernews Inc.

\subsubsection{Weathernews}

Weathernews Inc. supplies many small citizen-participatory services to increase the accuracy of the weather forecast. Citizen volunteers take photographs of the sky, post them, and provide weather information by means of the official application, Weathernews Touch. Among the services in the application, we focused on the basic tasks that are for free. Although the service is provided all over the world, it mainly services Japan. Weathernews provides weather information on live videos through the official application in addition to webinars and offline seminars [27]. The application has a function that allows users to comment. The comments are often not scientific discussions but views about the photographs. Approximately 6.5 million reporters use the application, and in the region of 30,000 people post weather information daily together with photographs [28]. On September 16, 2013, there were 56,033 posts when Typhoon No. 18 made a landfall near Aichi [29]. Some users came to our KOS meetup and discussed this project. According to Haklay's classification, posting a photo of the sky and providing weather information is crowdsourcing (Level 1) [18] because no additional training is required. Weathernews makes its profit from paying members of its official application, providing weather information to broadcasts, and so forth.

\subsubsection{Aurora 4D Project}

Aurora $4 D$ Project is a research project consisting of an online data collection of photographs of aurora with location information and offline workshops in order to find the description of 
aurora in Japanese historical documents. This project started as an interdisciplinary collaboration of the National Institute of Polar Research and the National Institute for Japanese Literature in 2015 with support from the SOKENDAI, after its prototype began with the interdisciplinary collaboration of space scientists and historians at Kyoto University in 2014, with the support of the Unit of Synergetic Studies for Space [30]. Researchers have published various academic outcomes [31-34]. The knowledge is utilized to combat disasters caused by extreme solar eruptions (or space weather events). According to Haklay's classification [18], we classified the project as crowdsourcing (Level 1) for taking photographs and distributed intelligence (Level 2) for reading Japanese historical documents; skills pertaining to reading Japanese historical documents depend on which type of documents volunteers read (e.g., translation in modern Japanese: level 1; original manuscripts in medieval Japanese or Sino-Japanese: level 2). The project is supported by the Center for the Promotion of Integrated Sciences of SOKENDAI.

\subsubsection{Finding Slugs Project}

Finding Slugs Project aims to investigate the distribution of alien great grey slugs (Limax maximus) in Japan [35, Fig. 2]. Citizen volunteers take pictures of slugs and post them with information about the location on Twitter or via e-mail. While the project website provides information on how to distinguish between species of slugs, the participants can post any species, including great grey slugs. A biologist organizes the project and determines the species of the particular slug found in the photographs. More than 300 reports from all over Japan had been posted by November 2017 [personal communication]. Using Haklay's classification [18], we classified this project as crowdsourcing (Level 1) and distributed intelligence (Level 2) for the participants who cannot and can distinguish slugs, respectively.

\subsubsection{Minna De Honkoku ("Transcribe With Everyone")}

The palaeoseismology research group of Kyoto University launched the project, Minna De Honkoku. The objective is to transcribe old records of earthquake disasters that were written in old Japanese characters with citizens and utilize the information so as to prevent future disasters [36, 37, Fig. 3]. One of the main members developed the official website. All the historical materials are prepared by researchers and because participants need some degree of mastery to read old characters, the project is classified as distributed intelligence (Level 2) according to Haklay's classification [18]. The project offers two learning opportunities; one is a free official learning application, KuLA, that assists beginners in learning old Japanese characters by themselves, and the other involves a function in which advanced users correct the transcriptions of beginners on the project site. The project has collaborated with Niconico Douga (DWANGO Co., Ltd.) on several occasions, which is a video sharing web media company that is gaining popularity among the subcultural people in Japan. On July 29, 2017, for example, 92,834 people watched a real-time movie in which organizers carried out transcriptions for 24 hours [38]. Users can communicate with others on an online discussion forum. By November 2017, more than three million old Japanese characters had been transcribed. It is noteworthy that up to approximately $88 \%$ of the transcribed material ( 2.67 of 3.05 million letters) was completed by $3 \%$ of all the users (calculated by the authors using data from the project website on October 25, 2017). Part of the project is supported by Grants-in-Aid for Scientific Research. 
(a)

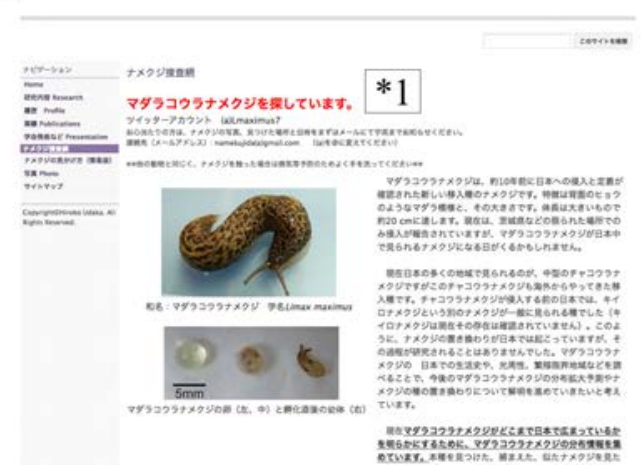

(b)

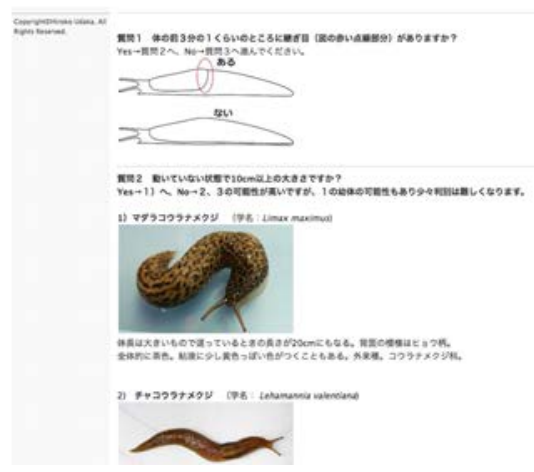

Figure 2: Website of Finding Slugs Project [35]. Top page (a) and the information page for distinguishing species of slugs (b). ${ }^{*} 1 \mathrm{We}$ are looking for great grey slugs.

Copyright: Hiroko Udaka.

(a)

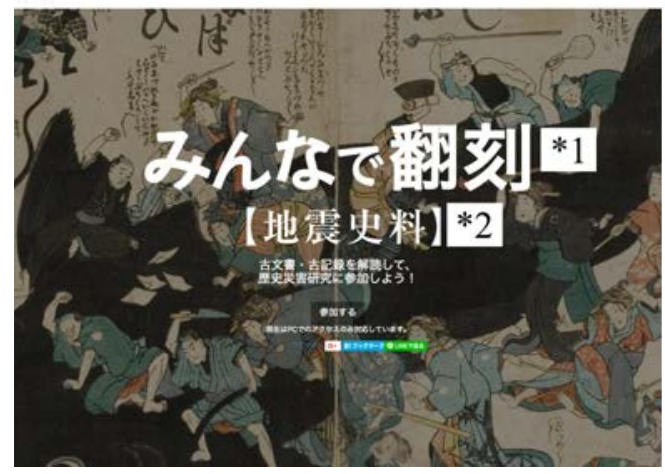

(b)

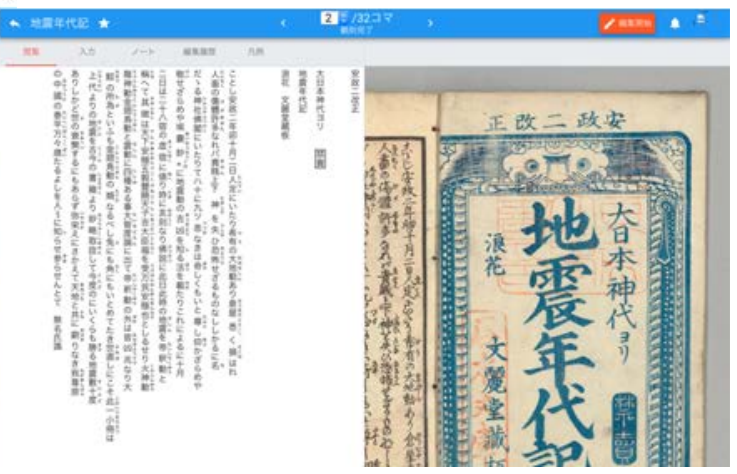

Figure 3: Website of Minna De Honkoku [36]. Top page (a) and task page (b). Historical documents are presented on the right and participants transcribe on the left in (b). *1 Minna De Honkoku, $* 2$ Historical documents of earthquakes.

Courtesy: Earthquake Research Institute, University of Tokyo.

(a)

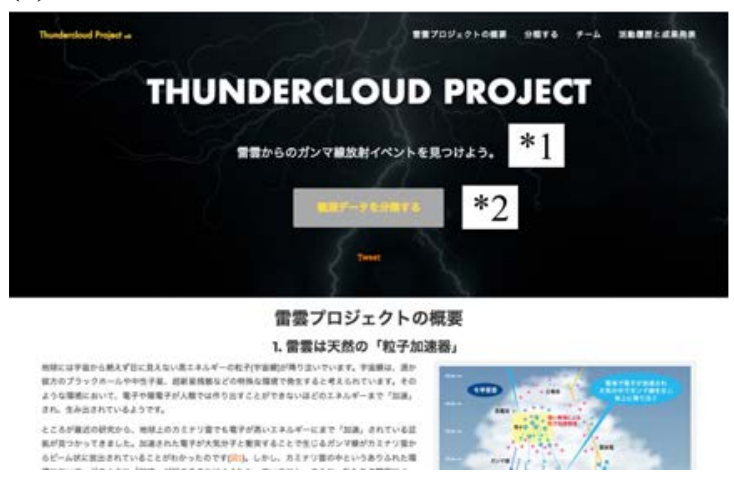

(b)

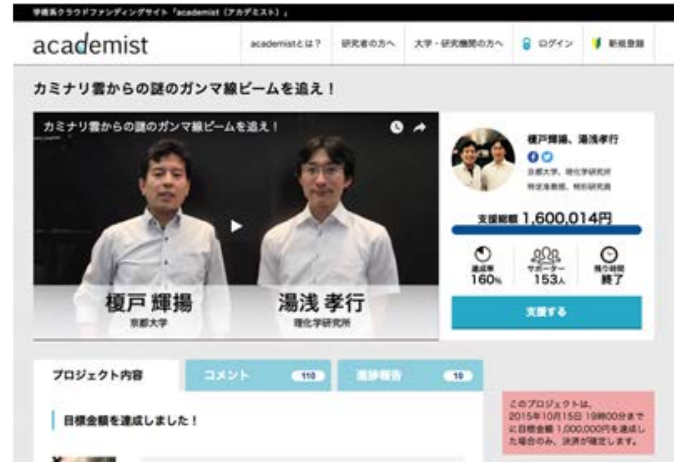

Figure 4: Website of Thundercloud Project introduces the research and provides visitors with a web application for the classification task (a) [39]. Webpage for crowdfunding at Academist

(Copyright: Academist, the academic crowdfunding platform) (b) [40]. *1 Hunting for gamma-ray beam from thundercloud. *2 Classify the observed data. 


\subsubsection{Thundercloud Project}

High-energy astrophysicists, including one of the authors, launched a new project so as to observe gamma rays from powerful winter thunderstorms and lightning along the Sea of Japan [39]. In 2015, two researchers of this group took on the challenge of academic crowdfunding via a private company, Academist Inc., to request financial aid for the project from citizen supporters [40, Fig. 4]. Advertising via social network services such as Twitter, Facebook, and various websites helped raise a total of $1,600,000$ Japanese yen (corresponding to $\$ 14,3000$ ) after a limited period of two months. The group developed radiation detectors that consist of crystal scintillators and a special data acquisition system and installed them at several observation sites along the ocean-side area in Japan [41]. The group monitors the radiation environment, which is designed to be remotely uploaded to the project website. Citizen volunteers are expected to classify radiation events and weather photos on the website. According to Haklay's classification [18], this project was classified as distributed intelligence (Level 2) as training is needed to read and comprehend radiation history. The project received funds through crowdfunding (Academist) and Grants-in-Aid for Scientific Research.

\subsubsection{Safecast}

Safecast was launched after the Fukushima Daiichi nuclear disaster of 2011. The founders are Sean Bonner, Pieter Franken, and Joi Ito who had no previous expertise in radiation. The objective is to establish a sensor network that will allow people to use the collected data freely [42]. Citizen volunteers measure environmental radiation by means of Geiger counters and upload the information on the website. To make useful and original Geiger counters, the project team collected activity funds by means of crowdfunding. Volunteers organize offline workshops to teach about nuclear radiation and how to use Geiger counters [26]. As the activity has spread throughout the world, the obtained data are presented both in English and in Japanese. There are over 40 million data points available [43]. According to Haklay's classification [18], Safecast can be classified as participatory science (Level 3); citizens proposed the project, conduct data collection and analysis, and exchange information with specialists in the field of radiation [44]. The project raised funds through crowdfunding (Kickstarter) [42] and through the Shuttleworth Foundation [43].

\section{Discussion and Conclusion}

Eight crowd science projects, including six Japanese projects and two worldwide projects as references, were reviewed and compared based on online citizen participation and online activities with regard to the following factors: 1) topic for increasing entry; 2) Haklay's classification of citizen engagement; 3) super-volunteers for developing projects; and 4) online system for stimulating and motivating participants. We found that super-volunteers, in particular, are key players in the growth of projects with regard to their educational roles as supporters for beginners. Furthermore, online discussion forums play a major role in enhancing participants' active communication, which has led to fruitful discussions and achievements of the projects.

To draw attention from a wide range of people, the topics of projects have to be considered. A boundary object is able to draw the interest of multiple stakeholders, including citizens [25]. For 
example, the Finding Slugs Project focuses on specific living organisms (great grey slugs) that are linked to the invasive alien-species problems. Such environmental issues attract the attention of both researchers and non-academic stakeholders, such as local governments and farmers; accordingly, this is a boundary object. In addition to selecting topics as boundary objects, if project organizers plan to gather potential participants, it is also a good way of positioning varied topics onto a portal site. SciStarter is a worldwide portal site that comprises projects that encompass many different topics; for example, The Great Pumpkin Project may be viewed as a biological project and the Globe at Night as a social and atmospheric project [45]. If registered on SciStarter, a project can be recognized by the participants of other projects on the same site. Participants with broad interests may become involved in projects on a portal site [12]. Such a site has not been launched in Japan as yet.

By means of Haklay's classification [18], five of the six Japanese projects were classified as crowdsourcing (Level 1), distributed intelligence (Level 2), or both. Weathernews, the Finding Slugs Project, and the Aurora 4D Project have entry-level tasks classified as Level 1. Beginners can participate in the tasks without training. However, even if they devote themselves to the project to a greater extent, they have no chance of conducting more difficult but worthwhile tasks [18]. Twenty-six pictures had been collected in the Aurora 4D Project by November 2017. This project is similar to a preceding project called Aurorasaurus, which had hosted 950 auroral pictures posted on Twitter till 2015; these have been placed on its official website [46]. Whereas Aurorasaurus accommodates English and can be found throughout the world [46, 47], the Aurora 4 D Project accommodates only Japanese. In addition, aurora is not frequently seen in Japan [31, 33, 48]. Accordingly, this has resulted in fewer reports. However, it is scientifically important to observe aurora where not usually seen. There are a large number of participants and a large amount of collected data in Weathernews. We are of the view that this is because the topic, namely, the weather, is very popular among many people; users can take photos of the sky anytime and anywhere, and the activity is stably and continuously supported by a number of staff members of the private company, Weathernews Inc. The financial basis of their services is stable. It may be difficult for researchers to perform such services. Although projects classified as Level 1 often have limitations, there are still appropriate methodologies to keep the participants interested.

In Minna De Honkoku, large amounts of data have been processed. We are of the view that the project has acquired super-volunteers in a short period through rich online activities such as Niconico Douga and that the super-volunteers have completed most of the tasks; as noted previously, approximately $3 \%$ of the super-volunteers transcribed up to $88 \%$ of all the tasks (see 2.3.4). This proportion is similar to that found in Zooniverse, in which $4 \%-7 \%$ of the super-users did about $85 \%$ of the tasks. Future project organizers may employ these proportions as a useful criterion; in other words, they should include super-volunteers in their projects. Hanamaru-Maruhana National Census ("Bumblebee National Census") aims to investigate the distribution of bumblebees, including non-native species in Japan, with reference to bumblebee conservation and climate change [49]. The project has super-volunteers and has published scientific results [50].

Processing large quantities of data by super-volunteers is effective for continuing and achieving the aims of the project. However, this also deprives beginners the chance to devote time to their tasks and learn. If a super-volunteer contributes not only to data collection or processing but also to educating beginners, the bias can be reduced. We are of the view that an educational 
system where beginners learn by themselves or from advanced users leads to the development and sustainability of the projects. For example, volunteers of Safecast hold workshops voluntarily not only for data processing but also for the dissemination of its method of analysis. Minna De Honkoku employs a system on the project site where super-volunteers correct the transcriptions of other users. Super-volunteers are able to play their educational roles and contribute to the development of projects through such effective learning systems for beginners.

There are varied ways to increase and keep participants motivated. One is "gamification." Gamification is a user ranking; it is a process that integrates game mechanics in non-game contexts [23]. Minna De Honkoku has a user ranking on project websites. Users recognize the degree of their contribution to the project. User rankings may stimulate competitive minds, which enhances participant engagement and motivation. Official learning applications such as KuLa of Minna De Honkoku employ a game-like quiz system and are useful, especially for beginner participants. Weathernews has a comment function that is not employed for scientific discussion but for friendly communication among users. For some participants, receiving comments from other users may be a form of gamification; once users receive comments, they are likely to want more of them and consequently, they will post more pictures. The comment function may allow users to experience a sense of belonging to the project and may be beneficial in keeping citizens motivated in the relatively easy task of the Level 1 project. Another way to enhance motivation is through discussion. Face-to-face discussions during project workshops may encourage participation motivation. After a free and open discussion in the ideathon of the offline KOS workshop, 74\% of the participants answered that they would like to join crowd science projects [24]. A previous study suggested that an online discussion forum is also essential for enhancing user communication [51], which may lead to scientific discovery. In Galaxy Zoo, new galaxies called Green Pea were discovered by the participants through the forum [52,53]. A large amount of data is dealt with by the participants of Safecast and Minna De Honkoku, whose projects have discussion forums. We are of the view that the online discussion forums of the two projects increase participants' motivation. It may be more beneficial for future project planners to consider employing the techniques of gamification and a discussion forum.

A web system that maintains the quality of its data and enough long-term funds can increase its feasibility to conduct crowd science projects. Managing the quality of the collected and processed data is important. Individual data such as a snapshot image, for example, are shown to multiple volunteers on the web system in Zooniverse projects, and its consensus answer is adopted as the "last answer" [54]. It contributes to improving the accuracy of the data. Such a web system is necessary so as to realize the projects regardless of whether organizers build the web systems by themselves or not. In Safecast, Minna De Honkoku, Weathernews, and the Thundercloud Project, the developer of the web system was included in each group and could directly optimize the system by considering their goals. Preparing a budget is also necessary to realize projects. The Thundercloud Project covered the initial cost of research by crowdfunding (about \$14,300); however, this was merely temporary income. In Mosquito Alert, a crowd science project that surveys the distribution of Asian tiger mosquitoes in Spain, expenses totaled 300,000 Euro (about \$350,000) in two years [55]. Technical and financial support are essential for the development of crowd science in Japan.

Although further research is required to reveal the effects of the Japanese cultural background, we are of the view that Japanese crowd science projects might reduce barriers for beginners and 
afford them the freedom to join the project by using project characters. Some projects (cf. Minna De Honkoku, Weathernews, and Hanamaru-Maruhana National Census) have original, kawaii (which means "cute" in Japanese) characters who explain how to conduct tasks, explain the technical terms, and increase project publicity. In Zooniverse projects, there is no such character. It might suggest that Japanese project organizers consider kawaii characters would attract wider range of volunteers.

In this study, we reviewed and classified six Japanese crowd science projects based on online citizen participation. Although projects classified as Haklay's Level 1 (e.g., Weathernews) often have limitations of citizen participation, there are still appropriate methodologies to keep participants interested. We are of the opinion that super-volunteers play a key role in the development of projects and that gamification (user ranking, game-like learning application, and comment function) and discussion forums increase the motivation of participants. Technical and financial support are also necessary to increase the feasibility of projects. This knowledge may be beneficial for future project organizers to plan a new crowd science project in Japan and for universities and research institutes to support them. Many Japanese projects have only recently started and, thus, it is still unknown how much each factor will contribute to the final goal of the projects. Additional long-term research is required to determine the development of crowd science projects in Japan.

\section{Acknowledgement}

The first and second KOS workshops were financially supported by "Hyakka-Soumei" research grant of Kyoto University and the "Nakatsuji Foresight Foundation", respectively. Activities of T. E. was supported by the "Hakubi" project of Kyoto University. This study was supported by JSPS KAKENHI Grant Numbers 17K12966. We express our sincere gratitude to Yasuhito Abe, Takashi Hamaji, Yuta Hashimoto (Minna De Honkoku), Kiyoteru Morita and Hiroki Inoue (Weathernews), Hiroko Udaka (Finding Slugs Project), Hisashi Hayakawa (Aurora 4D Project), Ryosuke Shibato and Wataru Suehiro (Academist Inc.) for their valuable comments on our manuscript. We also thank Earthquake Research Institute at the University of Tokyo for providing the original figure of Fig. 3(a) and Fig. 3(b), MTRL KYOTO, and all the participants of the KOS meetups and workshops.

\section{References}

[1] OECD, Paris, France “Open science,” [Online]. Available: https://www.oecd.org/sti/outlook/e-outlook/stipolicyprofiles/interactionsforinnovation/opens cience.htm, Accessed: Nov. 22, 2017.

[2] European Commission, Brussel, Belgium “Open Science Monitor,” [Online]. Available: http://ec.europa.eu/research/openscience/index.cfm?pg=home\&section=monitor, Accessed: Nov. 22, 2017.

[3] N. Pontika, and P. Knoth, “Open Science Taxonomy,” [Online]. Available: figshare: https://doi.org/10.6084/m9.figshare.1508606.v3, Accessed: Nov. 22, 2017. 
[4] Kyoto University, Kyoto "Kyoto University adopts "Kyoto University Open Access Policy" (28 April 2015)," [Online]. Available:

http://www.kyoto-u.ac.jp/en/research/events_news/department/library/news/2015/150428_1 .html, Accessed: Jan. 23, 2018.

[5] A. Irwin, Citizen Science: A Study of People, Expertise, and Sustainable Development. New York, NY, USA: Routledge, 1995.

[6] J. Silvertown, “A new dawn for citizen science," Trends Ecol. Evol., vol. 24, no. 9, pp. 467-471, Jul. 2009.

[7] G. Newman et al., "The future of citizen science: emerging technologies and shifting paradigms," Front. Ecol. Environ., vol. 10, no. 6, pp. 298-304, Aug. 2012.

[8] M. J. Raddick et al., "Galaxy zoo: Exploring the motivations of citizen science volunteers," Astron. Educ. Rev., No. 9, vol. 1, pp. 1-27, Dec. 2009.

[9] Galaxy Zoo, “Galaxy Zoo,” [Online]. Available: https://www.galaxyzoo.org/, Accessed Nov. 11, 2017.

[10] M. Nielsen, Reinventing discovery: the new era of networked science. Princeton, NJ, USA: Princeton University Press, 2012.

[11] F. Grey, "The age of citizen cyberscience," CERN Courier, Bristol, UK, Apr. 29, 2009. [Online]. Available: http://cerncourier.com/cws/article/cern/38718, Accessed: Nov. 22, 2017.

[12] C. Franzoni, and H. Sauermann, "Crowd science: The organization of scientific research in open collaborative projects," Res. Policy, vol.43, no.1, pp.1-20, Aug. 2014.

[13] eBird, "Welcome to eBird," [Online]. Available: http://ebird.org/content/ebird/, Accessed Nov. 11, 2017.

[14] B. L. Sullivan, "The eBird enterprise: an integrated approach to development and application of citizen science," Biol. Conserv., vol. 169, pp. 31-40, Jan. 2014.

[15] R. Tinati et al., "Designing for citizen data analysis: a cross-sectional case study a multi-domain citizen science platform," in Proc. 3rd Ann. ACM Conf. Human Factors in Computing Systems, 2015, pp. 4069-4078.

[16] Zooniverse, "All publications," [Online]. Available: https://www.zooniverse.org/about/publications, Accessed Nov. 11, 2017.

[17] Research Council UK, Swindon, UK, "Research councils UK -public insight research," [Online] Available: http://www.rcuk.ac.uk/documents/publications/rcukpublicinsightproject-pdf/, Accessed: Nov. 22, 2017. 
[18] M. Haklay, "Citizen science and volunteered geographic information: Overview andtypology of participation", in Crowdsourcing geographic knowledge, D. Sui, S. Elwood, and M. Goodchild, Eds. Dordrecht, Netherlands: Springer, 2013, pp. 105-122.

[19] R. Tinati, E. Simperl, M. Luczak-Roesch, M. Van Kleek, and N. Shadbolt, "Collective Intelligence in Citizen Science - A Study of Performers and Talkers," in Proc. Collective Intell., 2014, pp. 4-7.

[20] T. Phillips, M. Furguson, M. Minarchek, N. Porticella, and R. Bonney, Users guide for evaluating learning outcomes from citizen science, Ithaca, NY: Cornell Lab of Ornithology, 2014.

[21] H. Sauermann, and C. Franzoni, "Crowd science user contribution patterns and their implications,” Proc. Nati. Acad. Sci., vol. 112, no. 3, pp. 679-684. May. 2015.

[22] Zooniverse, "Who are the zooniverse community? We asked them...," [Online]. Available: https://blog.zooniverse.org/2015/03/05/who-are-the-zooniverse-community-we-asked-them/, Accessed Jan. 23, 2018.

[23] A. Eveleigh, C. Jennett, S. Lynn, and A. L. Cox, "I want to be a Captain! I want to be a Captain!: Gamification in the Old Weather Citizen Science Project," in Proc. 1st Int. Conf. Gameful Design, Research, and Applications, 2013, pp. 79-82.

[24] E. Ono, Y. Ikkatai, and T. Enoto, "Encouraging Citizen Motivation of Crowd Science: A Case Study of Kyoto Open Science Activities," in Proc. 6th Int. Congr. Advanced Applied Informatics, Hamamatsu, 2017, pp. 116-119.

[25] S. L. Star, and J. R. Griesemer, "Institutional Ecology, 'Translations' and Boundary Objects: Amateurs and Professionals in Berkeley's Museum of Vertebrate Zoology, 1907-39," Soc. Stud. Sci., vol. 19, no. 3, pp. 387-420, Aug. 1989.

[26] MTRL KYOTO, Kyoto, Japan, “Know, make and measure. Let's learn how to communicate with radiation: first workshop by multinational volunteer team Safecast in Kyoto (Japanese)," [Online]. Available: https://mtrl.net/kyoto/events/161023_safecast/, Accessed Nov. 11, 2017.

[27] Weathernews Inc., Chiba, Japan, "The history of weather reporter (Japanese)," [Online]. Available: http://weathernews.jp/ip/info/wxrepo10th/history/timeline/index.html, Accessed Nov. 11, 2017.

[28] Weathernews Inc., Chiba, Japan, "The use of SNS for disaster prevention. About Weathernews' efforts. (Japanese)," [Online]. Available: http://www.kantei.go.jp/jp/singi/it2/senmon_bunka/bousai/dai5/siryou4.pdf, Accessed Nov. $11,2017$.

[29] Weathernews Inc., Chiba, Japan, “Always with you,” [Online]. Available: https://jp.weathernews.com/news/3653/, Accessed Nov. 11, 2017. 
[30] H. Isobe, "The Solar Activity Surveyed from Historical Documents (Japanese)," Theastronomical herald, vol. 110, no. 7, pp. 451-454, 2017.

[31] H. Tamazawa, H. Hayakawa, and K. Iwahashi, "Astronomy and Intellectual Networks in the late 18th Century in Japan: A Case Study of Fushimi in Yamashiro," Hist. Sci., no. 26, vol. 3, p.172, 2017.

[32] H. Hayakawa et al., "The earliest drawings of datable auroras and a two-tail comet from the Syriac Chronicle of Zūqnīn,” Publ. Astron. Soc. Jpn., vol. 69, no. 2, Apr. 2017.

[33] H. Hayakawa et al., "East Asian observations of low-latitude aurora during the Carrington magnetic storm," Publ. Astron. Soc. Jpn., vol. 68, no. 6, Dec. 2016.

[34] R. Kataoka et al., "Historical space weather monitoring of prolonged aurora activities in Japan and in China," Space Weather, vol. 15, no. 2, pp.392-402, Feb. 2017.

[35] Finding Slugs Project, "Finding Slugs Project (Japanese)," [Online]. Available: https://sites.google.com/site/udakawebsite/madarakouranamekuji-limax-maximus, Accessed Nov. 11, 2017.

[36] Minna De Honkoku, "Minna De Honkoku (Japanese)," [Online]. Available: https://honkoku.org/, Accessed Nov. 11, 2017.

[37] Y. Kano et al., "Minna de Honkoku: online transcription project of earthquake-related historical documents," presented at the JpGU-AGU Joint Meeting 2017, Tokyo, Japan, May 20-25, 2017.

[38] DWANGO Co., Ltd., Tokyo, Japan, "Kyoto University $\times$ Niconico 24 hours of Minna De Honkoku (Japanese)," [Online]. Available: http://live.nicovideo.jp/watch/lv303440061, Accessed Dec. 4, 2017.

[39] Thundercloud Project, “Thundercloud Project (Japanese)," [Online]. Available: https://thdr.info/, Accessed Nov. 11, 2017.

[40] Academist, Tokyo, Japan, "Hunting for gamma-ray beam from thundercloud (Japanese)," [Online]. Available: https://academist-cf.com/projects/?id=16, Accessed Nov. 11, 2017.

[41] T. Enoto et al., "Photonuclear reactions triggered by lightning discharge," Nature, vol. 551, pp. 481-484, Nov. 2017.

[42] Safecast, "About Safecast (Japanese)," [Online]. Available: https://blog.safecast.org/about/, Accessed Nov. 11, 2017.

[43] A. Brown, P. Franken, S. Bonner, N. Dolezal, and J. Moross, "Safecast: successful citizen-science for radiation measurement and communication after Fukushima," J. Radiol. Prot., vol. 36, no.2, pp. S82-S101, Jun. 2016.

[44] Y. Abe, "Measuring for What: Networked citizen science movements after the Fukushima nuclear accident," Ph.D dissertation, Faculty of the USC graduate school, Univ. of Southern California, Los Angeles, CA, USA, 2015. 
[45] SciStarter.com, "scistarter, Science we can do together" [Online]. Available: https://scistarter.com/, Accessed Nov. 11, 2017.

[46] N. Case, E. MacDonald, S. McCloat, N. Lalone, and A. Tapia "Determining the accuracy of crowdsourced tweet verification for auroral research," Citizen Science: Theory and Practice, vol. 1, no. 2, pp. 1-9, Dec. 2016.

[47] E. A. MacDonald et al., "Aurorasaurus: A citizen science platform for viewing and reporting the aurora," Space Weather, vol. 13, no. 9, pp. 548-559, Sep. 2015

[48] J. L. Green, and S. Boardsen, "Duration and extent of the great auroral storm of 1859," Adv. Space Res., no. 38, vol. 2, pp. 130-135. Jan. 2006.

[49] Hanamaru Maruhana Project, "Hanamaru Maruhana Project (Japanese)," [Online]. Available: http://meme.biology.tohoku.ac.jp/bumblebee/index.html, Accessed Nov. 11, 2017.

[50] Y. Suzuki-Ohno, J. Yokoyama, T. Nakashizukuka, and M. Kawata, "Utilization of photographs taken by citizens for estimating bumblebee distributions," Sci. Rep., vol. 7, no. 11215, Sep. 2017.

[51] A. J. Barr, A. C. Haas, and C. W. Kalderon, "Citizen Scientist Community Engagement with the HiggsHunters project at the Large Hadron Collider," 2017. [Online]. Available: arXiv:1711.05148, 2017.

[52] C. Cardamone et al., "Galaxy Zoo Green Peas: discovery of a class of compact extremely star-forming galaxies," Mon. Notices Royal Astron. Soc., vol. 399, no.3, pp. 1191-1205, Nov. 2009.

[53] Galaxy Zoo, "Eight Years \& the 8th Paper: Green Peas - Living Fossils of Galaxy Evolution,” July 7, 2017. [Online]. Available: https://blog.galaxyzoo.org/tag/green-peas/, Accessed Nov. 11, 2017.

[54] A. Swanson, M. Kosmala, C. Lintott, and C. Packer, "A generalized approach for producing, quantifying, and validating citizen science data from wildlife images," Conserv. Biol., vol. 30, no. 3, pp. 520-531. Apr. 2016

[55] J. R. Palmer et al., "Citizen science provides a reliable and scalable tool to track disease-carrying mosquitoes,” Nat. Commun., vol. 8, no. 916, Oct. 2017. 